\title{
Optimization and Algorithm of Supply Chain Network Among Enterprise Alliances Based on Robust Model of Supply Chain Network Design
}

\author{
Yulan Zheng \\ School of Economics \& Management, Fuzhou, University, Fuzhou, Fujian, \\ 350116, China. \\ Yulanzh23@163.com
}

\begin{abstract}
Based on real situations of supply chain network among enterprise allianoes, this paper takes certain factors in every round of supply chain into consideration to establish robust model of supply chain network design. Before that, the strategy "decompositioncoordination" is adopted to get solutions optimizing supplychain system, putting focus on the analysis of supplier selection cost and decision-making cos of supply chain facilities, which is integrated and coordinated through activity based costing. After the model establishment, examples are used to illustrate practicability and effectuveness of the model and algorithm.
\end{abstract}

Keywords: supply chain, uncertain faetors, robust model, hybrid intelligent algorithm

\section{Introduction}

When economic society de velops in a high speed, market competition gradually becomes the competition of supply chain network among enterprise alliances [1]. Supply chain optimization requiresenterprise alliances to provide services through the Internet and to coordinate cooperative neans to improve profits and performances on the chain [2]. This is processed under uncertain environment which refers to uncertain factors turning up in every round of supply chain according to real situations in markets, including random demands from customers, vague operation expense and uncertain productive performance [3]. To decrease risks like ancertain supplement by making supply chain system more flexible and responsive, such an optimization combining with management is demanded to make use of technologies in management, information and process controlling. On one hand, with lower costs, supplier, manufacturer, retailer and transport enterprise are able to solve issues about logistics in and out of enterprises, mutually coordinating enterprises in every point [4]. On the other hand, resources from suppliers can be resorted to better respond to customer demands and enhance mutual cooperation and trust among joint enterprises [5].

But the question is how an enterprise builds its supply chain. Besides, it needs to figure out how to ensure supply chain structure containing supplier and detailed analysis of facility decision on the condition of low cost and stability, and how to optimize the management of supply chain network. This paper states in details about model approaches, building process of mathematical model and strategies of model solution, and applies random data to complement analysis based on real examples.

\section{Model Approach}

A supply chain network can be divided into four types, including supplier responsive for offering law materials, factory in charge of production, distribution center and consumer.

The chain is regarded as an abstract digraph consisted by nodes and arcs, while the above 
four types build nodes in the chain [6]. This paper does research on a system of multilayer and net-like supply chain containing more than a supplier, a factory, a distribution center and a consumer, which is presented as Figure 1 .

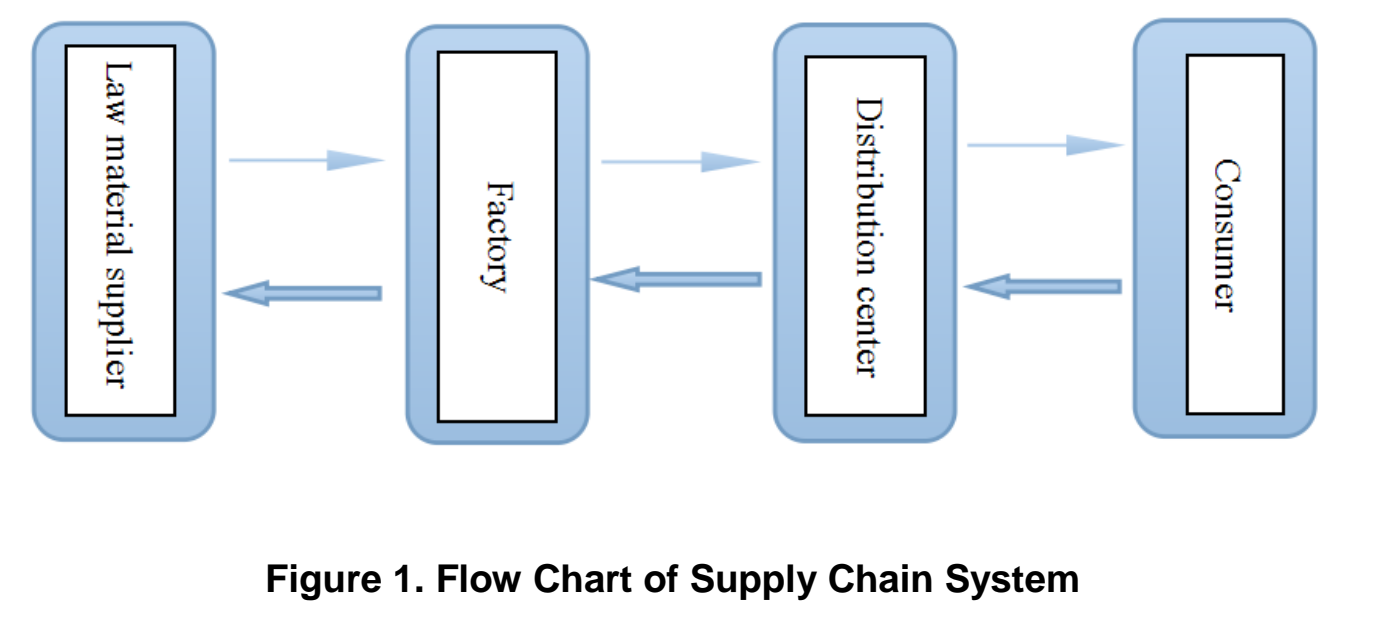

Since the system is complicated, strategy "decompostion-coordination" is used to optimize the system [7]. The first step is decomposition, meaning that the system is decomposed to several subsystems in lower class to implement local optimization. This paper mainly decomposes the target function, namely the minumum cost function of supply chain. The second is coordination; based on local optimization by sub-systems, overall target function, according to general objective of the gystem, is minimized to maintain satisfying solutions to realize global optimization the specific approach is performed below:

1). Systematically analyze is ues lo establish sub-model of supplier selection, namely minimum formula of cost, and sub-model of facihity decision, namely minimum formula of facility-decision cost.

2). Resort supplier selection and facility decision to minimize the mean of system overall cost, meaning to composite formula of cost and facility decision and come upon constraint conditions in reality; and build ptimized robust model for network design of supply chain.

3). Calculate the model by hybrid intelligent algorithm with the combination of random simulation and particle swarm algorithm to resolve algorithm of system model; and apply data randomly produced in the test of algorithm performances to carry out exampirical analysis.

\section{Model Establishment under Uncertain Environment}

To make statement convenient, model symbol and parameter are defined, resulting in three types of variables: regular variable, assigned variable and controlled variable. Please refer to Table 1 , Table 2 and Table 3.

Table 1. Regular Variable of Model Symbol and Parameter

\begin{tabular}{|c|r|c|r|c|}
\hline \multicolumn{2}{|c|}{ Regular Variable } & $\begin{array}{r}\text { Sy } \\
\text { Nbol }\end{array}$ & $\begin{array}{r}\text { Note } \\
\text { (all data are } \\
\text { natural numbers) }\end{array}$ \\
\hline Supplier collection & $\mathrm{A}$ & Supplier number & $\mathrm{a}$ & $\mathrm{a} \in \mathrm{A}$ \\
\hline Factory collection & $\mathrm{B}$ & Factor number & $\mathrm{b}$ & $\mathrm{b} \in \mathrm{B}$ \\
\hline $\begin{array}{c}\text { Distribution center } \\
\text { collection }\end{array}$ & $\mathrm{C}$ & $\begin{array}{c}\text { Distribution center } \\
\text { number }\end{array}$ & $\mathrm{c}$ & $\mathrm{c} \in \mathrm{C}$ \\
\hline
\end{tabular}




\begin{tabular}{|c|c|c|c|c|}
\hline Consumer collection & D & Consumer number & $d$ & $\mathrm{~d} \in \mathrm{D}$ \\
\hline $\begin{array}{c}\text { Raw material } \\
\text { collection }\end{array}$ & $\mathrm{E}$ & Raw material number & $\mathrm{e}$ & $\mathrm{e} \in \mathrm{E}$ \\
\hline Product collection & $\mathrm{F}$ & Product number & $\mathrm{f}$ & $\mathrm{f} \in \mathrm{F}$ \\
\hline $\begin{array}{c}\text { Possible situation } \\
\text { collection }\end{array}$ & $\mathrm{S}$ & $\begin{array}{c}\text { Possible situation } \\
\text { number }\end{array}$ & $\mathrm{s}$ & $\mathrm{s} \in \mathrm{S}$ \\
\hline
\end{tabular}

Table 2. Assigned Variables of Model Symbol and Parameter

\begin{tabular}{|c|c|c|}
\hline \multicolumn{3}{|c|}{ Assigned Variable } \\
\hline Meaning & $\begin{array}{l}\text { Sym } \\
\text { bol }\end{array}$ & Notice \\
\hline $\begin{array}{c}\text { Decision of supplier a for offering law } \\
\text { material e }\end{array}$ & Xae & "1" for "yes" and "0" for \\
\hline Decision of establishing factory $b$ & $\mathrm{Yb}$ & and " 0 " for \\
\hline Decision of founding distribution canter $\mathrm{c}$ & $\mathrm{Zc}$ & \\
\hline $\begin{array}{l}\text { Decision of distribution center c for offering } \\
\text { consumer d products }\end{array}$ & & $\mathrm{nc}$ \\
\hline Productive capability of factory $b$ & & \\
\hline Productive capability of distribution & & $\begin{array}{l}\text { aximum value of } \\
\text { capability }\end{array}$ \\
\hline
\end{tabular}

Table 3. Controlled Variables of Model Symbol and Parameter

\begin{tabular}{|c|c|}
\hline $\begin{array}{l}\text { Controlled Variable } \\
\text { Meaning }\end{array}$ & Symbol \\
\hline $\begin{array}{l}\text { The amount of raw material e that factory b purchasing from supplier a under } \\
\text { circumstance } s\end{array}$ & $G_{a b c}^{s}$ \\
\hline $\begin{array}{l}\text { The mount of product } f \text { that distribution center } \mathrm{c} \text { transporting from factory } \mathrm{b} \\
\text { under circumstance } \mathrm{s}\end{array}$ & $Q_{b c f}^{s}$ \\
\hline $\begin{array}{l}\text { The mount of product } \mathrm{f} \text { that distribution center } \mathrm{c} \text { delivering to consumer } \mathrm{d} \\
\text { under circumstance } \mathrm{s}\end{array}$ & $R_{c d f}^{s}$ \\
\hline
\end{tabular}

\subsection{Sub-model of Supplier Selection}

The cost of supplier selection mainly performs in purchasing costs, including price cost and transportation cost. Cost parameters of this sub-model are presented in Table 4.

Table 4. Cost Parameter Definition of Supplier Selection Sub-model

\begin{tabular}{|c|c|}
\hline Cost Parameter Definition of Supplier Selection Sub-model \\
\hline Meaning & $\begin{array}{c}\text { Sym } \\
\text { bol }\end{array}$ \\
\hline $\begin{array}{c}\text { Price of raw material e purchased from supplier a under circumstance s } \\
\text { Unit transportation cost of raw material e transported from supplier a to } \\
\text { factory b under circumstance s }\end{array}$ & $\beta_{a b e}^{s}$ \\
\hline Supply capability of supplier a offering raw material e & $\delta_{a e}$ \\
\hline Match relation between raw material e and product f & $\lambda_{e f}$ \\
\hline
\end{tabular}


Presuming $\forall s \in S, P_{1}$ refers to the product of unit-price and amount of purchasing cost, price cost or transportation cost, resulting in the following formula.

$$
P_{1}=\sum_{a} \sum_{b} \sum_{e}\left(\alpha_{a e}^{s}+\beta_{a b e}^{s}\right) G_{a b e}^{s}
$$

The establishment of formula (1) must consider relevant constraint conditions in reality, such as the value of supplier's capability $\delta_{a e}$ and the satisfaction of purchased materials demanded by production [8]. So under circumstance s, the formula for constraints among $G_{a b e}^{s}, \mathrm{Xae}, \lambda_{e f}$, and $Q_{b c f}^{s}$ is shown below.$$
\sum_{c} \sum_{f} \lambda_{e f} Q_{b c f}^{s} \leq \sum_{a} G_{a b e}^{s} \leq \delta_{a e} X_{a e}
$$

\subsection{Sub-Model of Facility Decision in Supply Chain}

For facility-decision cost of supply chain, it performs in four aspects, namely fixed operation cost, business-dealing cost, inter-facility transportation cost and purchasing cost, and they are presented as P2, P3, P4 and P5, respectively. Please refer to Table 5 lor the cost parameters of this sub-model.

Table 5. Cost Parameter Definition of Facility-Decision Sub-Model

\begin{tabular}{|c|c|}
\hline \multicolumn{2}{|c|}{ Cost parameter definition of facility-decision sub-model } \\
\hline Fixed operation cost of factory bander circumstance s & $v_{b}^{s}$ \\
\hline Fixed operation cost of distribution center c underircumstance s & $\varepsilon_{c}^{s}$ \\
\hline Unit cost of factory b produeing product f under circumstance s & $\kappa_{b f}^{s}$ \\
\hline $\begin{array}{c}\text { Unit operation cost of distribution center e ofproduct f under circumstance } \\
\text { s }\end{array}$ & $\mu_{c f}^{s}$ \\
\hline $\begin{array}{c}\text { Unit transportation cost of product fransported from factory b to } \\
\text { distribution center qunder circumstance s }\end{array}$ & $\sigma_{b c f}^{s}$ \\
\hline $\begin{array}{c}\text { Unit transportation cost of product delivered from distribution center c to } \\
\text { Unit punsumer dunder circumstance s }\end{array}$ & $\varpi_{b c f}^{s}$ \\
\hline Unit purchasing cost of distribution center c under circumstance s & $\Gamma_{b}^{s}$ \\
\hline
\end{tabular}

All calculations are carried out on the condition that $\forall s \in S$. If $\mathrm{P} 2$ refers to the sum of fixed operation costs of $\mathrm{b}$ and $\mathrm{c}$, then it is performed as the follows.

$$
P_{2}=\sum_{b} v_{b}^{s} Y_{b}+\sum_{c} \varepsilon_{c}^{s} Z_{c}
$$

Similarly, the following presents $\mathrm{P} 3$, the operation cost sum of $\mathrm{b}$ and $\mathrm{c}$.

$$
P_{3}=\sum_{b} \sum_{f} \sum_{c} \kappa_{b f}^{s} Q_{b c f}^{s}+\sum_{c} \sum_{f} \sum_{d} \mu_{c f}^{s} R_{c d f}^{s}
$$

When facility transported from $\mathrm{b}$ to $\mathrm{c}$ and from $\mathrm{c}$ to $\mathrm{d}$, it comes across unit transportation costs whose sum is performed as $\mathrm{P} 4$.

$$
P_{4}=\sum_{b} \sum_{f} \sum_{c} \sigma_{b c f}^{s} Q_{b c f}^{s}+\sum_{c} \sum_{f} \sum_{d} \varpi_{c d f}^{s} R_{c d f}^{s}
$$

While P5 means the sum of unit purchasing costs of b and c, which is shown in the following. 


$$
P_{5}=\sum_{b} \Gamma_{b}^{s} M_{b}+\sum_{c} \Psi_{c}^{s} N_{c}
$$

Considering relevant constraint conditions of formula (2), (3), (4) and (5), the following three inequalities come into being.

$$
\sum_{b} Q_{b c f}^{s} \geq \sum_{d} R_{c d f}^{s}
$$

(1) The amount of purchase is no less than that of shipment.

$$
\sum_{b} Q_{b c f}^{s} \leq M_{b}
$$

(2) The overall production of a factory is not supposed to exceed its production capability.

$$
\sum_{b} \sum_{f} Q_{b c f}^{s}+\sum_{c} \sum_{f} R_{c d f}^{s} \leq N_{c}
$$

(3) The amount sum of purchase and shipment of a distribution center is no more than its throughput capacity.

\subsection{Resorted Model of Supply Chain Network Design}

Presuming $\forall s \in S$, the cost of resorted model is performed as Ps, the sum of $\mathrm{P} 1, \mathrm{P} 2, \mathrm{P} 3$, P4, and P5, showing as $P_{s}=P_{1}+P_{2}+P_{3}+P_{4}+P_{5}$ To be more detailed, a new formula is born.

$$
\begin{aligned}
& P_{s}=\sum_{a} \sum_{b} \sum_{c}\left(\alpha_{a e}^{s}+\beta_{a b e}^{s}\right) G_{a b}^{s}+\sqrt{\gamma_{b}^{s}} Y_{b}+\sum_{c}^{s} \xi_{c} \Phi \\
& \sum_{b} \sum_{f} \sum_{c} \kappa_{b f}^{s} Q_{b c f}^{s}+\sum_{c} \sum_{f} \sum_{d} \mu_{d j}^{s} R_{d}+\sum_{b} \sum_{f} \sum_{c} \sigma_{b c f}^{s} Q_{b c f}^{s}+ \\
& \sum_{c} \sum_{f} \sum_{d} \varpi_{c d f} R_{c d f}^{s}+\sum_{b} \Gamma_{b}^{s} \mathbb{C}_{b} \sum_{c} \Psi_{c}^{s} N_{c}
\end{aligned}
$$

Since the establishment of all formulas is based on circumstance s, it is necessary to reconsider S collection. The occurrence of each circumstance has different probability, ${ }_{\text {so }} \rho_{s}$ is introduced to be used as the probability, aiming to build robust model (ROM) of resorted supply chan.

$$
\text { (2) } \min P=\sum_{s} \rho_{s} P_{s}
$$

Formula (6) is alsoconstraint according to the above four conditions.

\section{Example Analysis}

Because the complicated project remains uncertain, this paper applies simulation to calculate vague target functions and test random constraint. Besides, simulation technology and part cle swarm optimization (PSO) are integrated to form hybrid intelligent algorithm to resolve values of robust model, which simplifies the calculation. PSO is a way to realize artificial intelligence by imitating group behaviors of natural creatures; in particular, this paper adopts foraging behaviors of birds, referring to group optimization through mass collaboration among bird groups. Firstly, PSO initializes random particles meaning single bird group; secondly, iterative screening is complemented based on bird groups' speeds and locations to constantly update individual optimum; finally, overall optimum is maintained based on combination of all optimums [9].

Compared to genetic or immune optimization algorithm, hybrid intelligent algorithm based on PSO is highlighted by real number coding, which is easy to operate and realize. Thus the algorithm is witnessed with its promising prospects in optimizing issues [10].

For example, a supply chain network containing 3 suppliers (a1, a2, a3), three factories 
(b1, b2, b3) and three distribution centers $(\mathrm{c} 1, \mathrm{c} 2, \mathrm{c} 3)$ for selection is made to meet demands of four consumers $(\mathrm{d} 1, \mathrm{~d} 2, \mathrm{~d} 3, \mathrm{~d} 4)$. According to 1:1:1 ratio, three kinds of raw materials is supposed to produce one product whose demand from consumers is called random variable having probability distribute uniformly in [160,20], [200,10], [220,20] and [260,20]. Matching normal distribution, all costs, including raw material price, transportation cost, operation cost of distribution center, purchasing cost, production cost and operation cost, are uniformly distributed in [10,5], [5,2], [10,5], [20,10] and [5,2], respectively.

If four demands are crossly combined with only one kind of cost, four different circumstances turn up. Presuming that the probability of each circumstance is $25 \%$, fixed operation cost of a factory and distribution under each circumstance will be respectively 10000 and 8000. Making the number $(\mathrm{N})$ of particle swarm equal to50, operating algebra 200 and the time of vague simulation 3000, only one robust solution of supply chain network design is obtained under four circumstances according to robust model of hybrid intelligent algorithm mentioned above. While the most probability is 0.85 ; so the final selections are supplier a1, a2 and a3, factory b2 and b3 and distribution center $\mathrm{c} 1$ and $\mathrm{c} 2$.

\section{Conclusion}

Supply chain network among enterprise alliances is found with uncertain costs and consumer demands. Taking consumers' random denands, vague operation cost and uncertain production capability into consideration, this paper applies uncertain project and integrates supplier selection and facility decision to establish robust nodel of supply chain network design. Besides, hybrid intelligent algøithm for model solutions is created based on the combination of random simulation and PSO. With illustration of a real example, this paper proves the practicability and effectiveness of the model and algorithm which effectively reduce market risks for enterprise alliances and improve cooperation and optimization of those alliances in supply chains.

\section{Acknowledgement}

Project supported by the National Natural Science Foundation of China (Grant No. 71171054).

\section{References}

[1] D. Ye, "Supply chain networ in the view of complicated network", Journal Modern Management Science, vol. 8, (2011), pp. 111-113

[2] F. Sheng, "Optimal aesign of robust supply chain network under demand uncertainty", Journal Science Technology and Engineering, vol. 11, (2012), pp. 2649-2654.

[3] Y. X. Yang, Y.B. Tang, Z. Y. Wu and C. X. Hu, "Network design model for remanufacturing closed-loop supply chain competition", Journal of Mechanical Engineering, vol. 50 no. 20, (2014), pp. 205-212.

[4] J. F. Tian, M. Yang and J. F. Yue, "Research on supply chain network design model with regret value", Journal of Industrial Engineering and Engineering Management, vol. 26 no. 1, (2012), pp. 48-55.

[5] Y. M. G.i, B. G. Gong and Y. M. Cheng, "Robust optimization and algorithm of supply chain network with uncertain conditions", Journal Statistics and Decision, vol. 8, (2011), pp. 172-174.

[6] L. P. Yu, X. Y. Huang and J. W. Xu, "Multi-objective robust operation model for supply chain with uncertain capital cost", Journal of Industrial Engineering and Engineering Management, vol. 24 no. 3, (2010), pp. 98-102.

[7] Y. Dai and Z. F. Wang, "Profit model of dominant enterprise in supply chain with uncertain conditions", Journal Commercial Times, vol. 5, (2010), pp. 18.

[8] Y. H. Xing and B. H. Jiang, "Simulation analysis on the influence of supply chain network robustness based on logistic factors", Journal Science and Technology Management Research, vol. 32 no.18, (2012), pp. 226-230.

[9] X. Zhao and J. P. Dou, "Hybrid particle swarm algorithms for solving design problems of agri-food supply chain network", Journal of Industrial Engineering and Engineering Management, vol. 27 no. 4, (2013), pp. 169-177. 


\section{Author}

Yulan Zheng, Received the Ms. degree in School of Management, Fuzhou University in 2009. Now she is the lecture teacher in Fuzhou University.

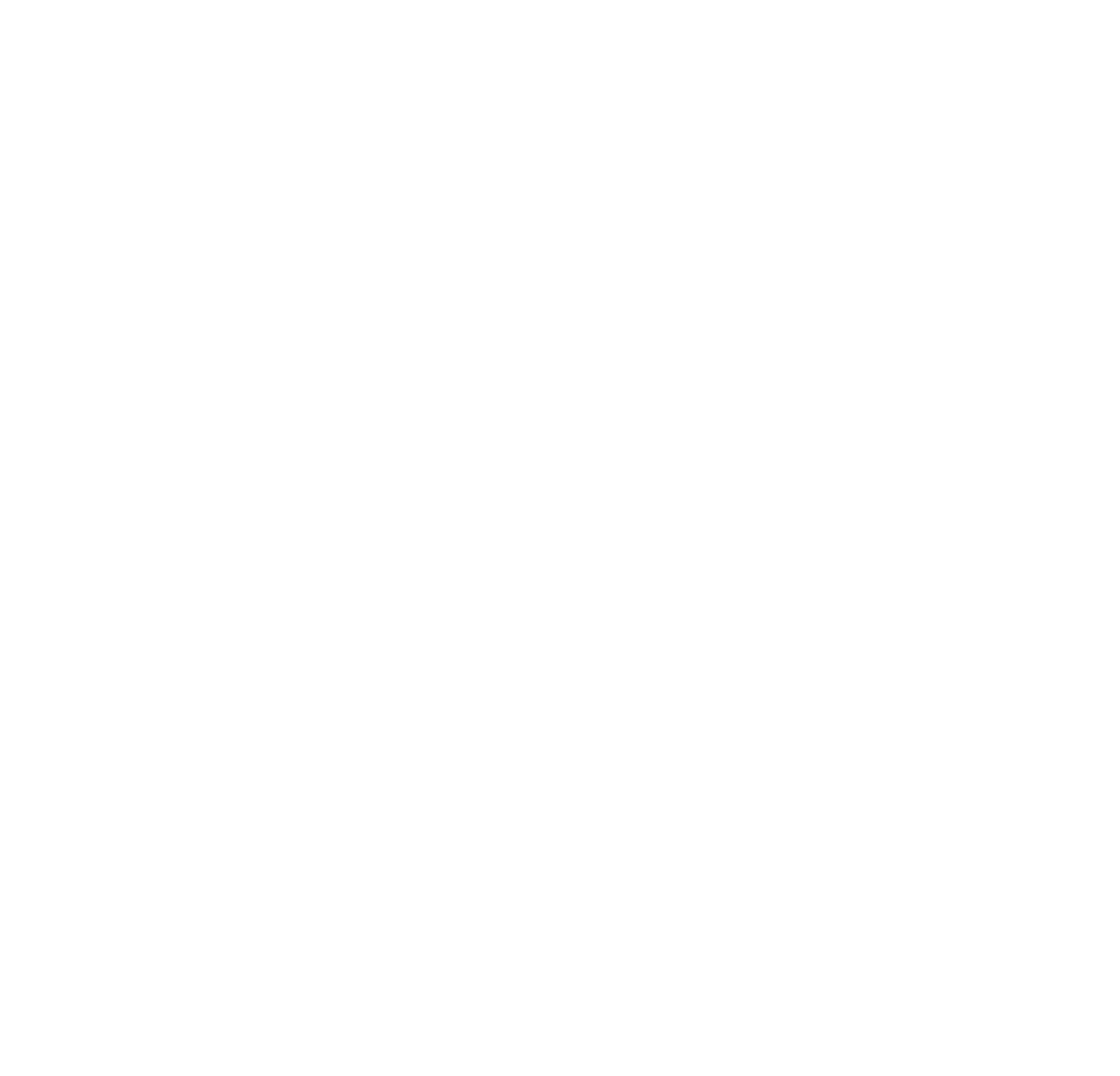


International Journal of Multimedia and Ubiquitous Engineering

Vol.11, No.9 (2016)

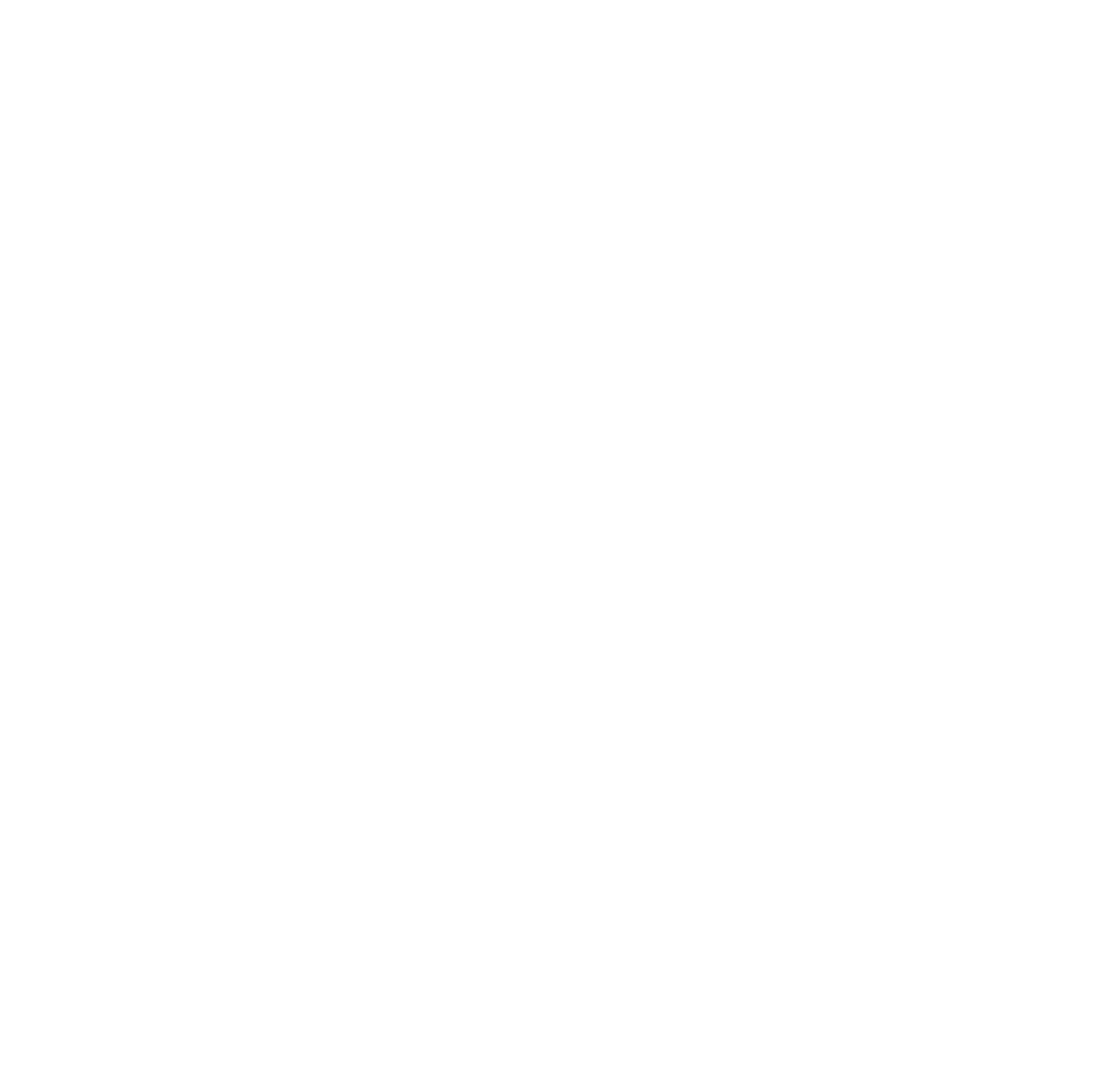

